\title{
The Role of Hope and Self-efficacy on Nurses' Subjective Well-being
}

\author{
Ruiming Liu ${ }^{1}$, Pan Zeng ${ }^{1} \&$ Peng Quan ${ }^{1}$ \\ ${ }^{1}$ Guangdong Medical University, Dongguan, China \\ Correspondence: Peng Quan, Mailbox No. 1306, Guangdong Medical University, Songshanhu Lake, Dongguan \\ 523808, China. Tel: 86-769-2289-6266. E-mail: pn2001@21cn.com
}

Received: January 26, 2018

Accepted: February 2, $2018 \quad$ Online Published: March 20, 2018

doi:10.5539/ass.v14n4p18

URL: https://doi.org/10.5539/ass.v14n4p18

\begin{abstract}
Although subjective well-being is considered important for nurses, the relationship between hope, self-efficacy, and subjective well-being among nurses has rarely been assessed. This study purposes to explore the relationships between hope, self-efficacy, and subjective well-being. The analysis relies on data from 1757 female nurses in 3 hospitals in China. Nurses completed a demographic form, General Self-efficacy Scale, Hope Scale, General Well-Being Schedule. A mediate model of the hypothesized relationships between the constructs was tested. Significant direct relationships of hope, self-efficacy, and subjective well-being were displayed. Mediation analyses reveal that the impact of self-efficacy on subjective well-being is partially mediated by two components of hope, agency and pathways. Hope was shown to be a key mediator for the relationships between self-efficacy and subjective well-being. These findings advance current understandings on the hopeful thinking in nurses.
\end{abstract}

Keywords: self-efficacy, hope, subjective well-being, mediation analysis

\section{Introduction}

Subjective well-being (SWB) is one of the most important indicators of people's evaluations of their lives. SWB includes optimism, life satisfaction, and positive emotions. SWB has been considered affect various domains of life such as work performance, mental health (Diener \& Ryan, 2009). For nurses, SWB is associated with their life satisfaction and the quality of nursing services (Bégat, Ellefsen, \& Severinsson, 2005). Increased workloads and job demands contribute to decreases in' SWB and higher levels of burnout in nurses. Previous research has focused on normal populations, yet research on nurses' SWB is relatively scant. It is particularly valuable to study nurses' SWB.

Self-efficacy is a belief that one can effectively deal with hardships and reach goals (Bandura, 1997). High self-efficacy is related to high SWB and good physical condition, while low self-efficacy is related to low SWB and depression (Weiss, Freund, \& Wiese, 2012). People tend to avoid activities that they cannot handle, and involved in situations that they can cope with. Research indicated that nurses' self-efficacy influences the quality of their patient care (Dunn, Osborne, \& Link, 2014). Nurses with low self-efficacy often lack confidence in communicating with patients. Therefore, they failed to provide medical care that met patients' needs (Stump, Husman, \& Brem, 2012).

Hope is a cognitive construct which reflects people's motivation and capacity to strive toward personal goals (Snyder et al., 2002). Hope and self-efficacy are different constructs. Self-efficacy means the expectancy that one can perform behaviors, whereas hope refers the expectancies that one can attain goals. Psychometric study shows that hope includes two important dimensions: agency and pathways (Geraghty, Wood, \& Hyland, 2010). Agency reflects a person's perceived capability to actively and constantly engage in goal attainment. Pathways instead refers to a person's perceived capability to generate the necessary routes that aids in goal attainment(Yavas, Babakus, \& Karatepe, 2013). A loss of hope often leads to losses, illness, impoverishment and life-threatening situations (Herth, 1990). When hope is lost, there is no reason to work hard to leave adverse situations, because there is no way out (Shea \& Hurley, 1964).

Study indicated hope predicts self-efficacy and optimism (Magaletta \& Oliver, 1999). Hope, self-efficacy, and optimism are related. Hopeful person incline to have a high sense of self-efficacy (Waddell et al., 2015). In bad situations, individuals with high self-efficacy would find alternative new goals and focus on those new goals. Therefore, they would reduce mental suffering that result from the unattainable goals. Hopeless person have no 
expectation that anything can help them out of their bad situations. Thus, hopeless person do not set goals. Also, hope significantly predicts SWB (Alarcon, Bowling, \& Khazon, 2013). There is a significant relationship between hope and life satisfaction. Hopelessness creates low self-efficacy and poor SWB (Steca et al., 2014). Moreover, faith, relationships, helping others and positive thinking helped people to have hope, hope had a positive influence on their job satisfaction (Duggleby, Cooper, \& Penz, 2009). It is reasonable to deduce that hope can play a role as a mediator between self-efficacy and SWB. Further understanding of the concept of hope in nurses may help to develop strategies to reduce burnout and increase SWB. There is a need to understand the underlying mechanism of this relationship.

This study aimed to investigate the associations between self-efficacy, SWB, and hope, especially for nurses by means of mediation analysis. The research questions were as follows: (i) Do the two components of hope (agency and pathways) affect self-efficacy and SWB? (ii)How do the constructs of agency and pathways, self-efficacy, and SWB interrelate? We hypothesize that agency and pathways would play a mediation role between these relationships. Based on the theoretical knowledge mentioned above, the following hypotheses were formulated: Hypothesis $1(\mathrm{H} 1)$ : self-efficacy $(X)$ positively affects SWB $(Y)$. Hypothesis $2(\mathrm{H} 2)$ : agency $\left(M_{1}\right)$ and pathways $\left(M_{2}\right)$ play mediation roles between self-efficacy and SWB.

\section{Method}

\subsection{Participants}

The data was gathered from 1757 female nurses in 3 hospitals located in two cities (Dongguan and Zhanjiang) of China between June and September 2015. Their average age was 31.57 \pm 5.37 years (range from 23 to 37 years). 1124 had a four-year college education, others had community college education. Participants were all voluntary. They were informed the procedure of this study. The study procedure was reviewed by the institutional review board of Guangdong medical university (ethical approval number: PJ2013039). Researchers distributed inform consent forms and instruments to participants. All participants were not currently undergoing treatment for a psychological disorder. It took about 20 minutes to fill out the questionnaire. The participants were each given 2 USD for their participation. Participants were free to withdraw at any time without penalty or loss of benefits. Questionnaires were distributed to the participants. 146 incomplete questionnaires were excluded. The response rate was $91.7 \%$.

\subsection{The Measures}

Self-efficacy. 10 items comprise General Self-efficacy Scale (Zhang \& Schwarzer, 1995). Participants indicate their agreement with statements on a 4-point Likert scale ( $1=$ Not at all true, $4=$ Exactly true). For example: "I can always manage to solve difficult problems if I try hard enough". The General Self-efficacy Scale has a reported Cronbach's $\alpha$ between .75 and .94 (Löve, Moore, \& Hensing, 2012). In this study, the Cronbach's $\alpha$ was found to be acceptable at 68 .

Hope. Adult hope scale (AHS) is a 12-item measure of a respondent's level of hope, four are distracters, four are agency thinking, and for are pathways thinking. Subjects respond on an eight point continuum $(1=$ definitely false, to $8=$ definitely true). The scale is divided into two subscales that comprise Snyder's cognitive model of hope: (1) agency (i.e., goal-directed energy) and (2) pathways (i.e., planning to accomplish goals). For example: "I can think of many ways to get out of a jam (Pathways)", "I energetically pursue my goals (Agency)". Cronbach's $\alpha$ have been reported ranging from.74 to .84 (Chan, Pittman, \& Munoz, 2013). In this study, the Cronbach's $\alpha$ was found to be acceptable at .62(agency), and .68(pathways).

Subjective well-being. The General Well-Being Schedule is a widely used self-reported questionnaire measuring SWB. It consists of 18 items, 14 items 6-point Likert scale, and 4 items are 10-point Likert scale. For example: "Have you been bothered by nervousness or your nerves". The total score ranges from 0 to 110 . High scores represent better well-being. The GWB is hypothesized to contain six dimensions: anxiety, depression, general health, positive well-being, self-control, and vitality. There is a reported Cronbach's $\alpha$ ranging from .68 to .85 (Taylor et al., 2003). In this study, the Cronbach's $\alpha$ was found to be acceptable at .88 .

All three measures have an expert panel back-translation procedure. Measures have been translated into Chinese and translate it back into English and compare the two.

\subsection{Data Analysis}

Data analyses were carried out using SPSS 23.0. To assess common method bias, we employed Harman's one-factor test. Cronbach's $\alpha$ was calculated to assess internal reliability. The correlational relationships between self-efficacy, hope and SWB were described by Pearson correlations. To test whether hope mediates the relationship between self-efficacy and SWB, the Preacher-Hayes procedure with bootstrap analyses was used 
(Hayes, 2013). Bootstrapping method was used to assess significance of indirect effects of self-efficacy on SWB through hope.

\section{Results}

In current study, all variables were collected from same respondent on same time. In this way, data were exposed to potential for common method bias (Rigtering \& Weitzel, 2013). We conducted a post hoc test of the common method bias. The Harman's single factor test is indicated if a single factor emerges as a dominant factor explaining most of the variance $(>50 \%)$ in the dataset. In the current study, the unrotated principal component analysis of all items with a single factor solution yielded 10 factors with an eigenvalue larger than the value of 1 . Moreover, these 10 factors explained a total of $51.36 \%$ variance. Furthermore, the factor with the greatest eigenvalue only accounted for $21.08 \%$ variance. It provided evidence that common method bias was not driving our findings.

The relationships among self-efficacy, agency, pathways and SWB were investigated by Pearson correlation. All variables are positively related ( $r$ s range from .56 to .73 , ps $<.01$ ).

To examine the mediation model we proposed in Hypothesis 2, we conducted a mediation analysis. Firstly, All three models are significant $\left(F_{M 1}=945.790, F_{M 2}=1950.558, F_{\mathrm{Y}}=502.018\right)$. We then applied the Preacher-Hayes procedure "process", with bootstrap analyses based on 5,000 resamples (Hayes, 2013). As shown in Table 3, both mediation effects through agency and through pathways are significant. The direct effect from self-efficacy to SWB is also significant. All effects are positive. The results suggest a partially mediation, which means mediated effect and direct effect both exist (Zhao, Lynch, \& Chen, 2010).

Table 1. Mediation Analysis Results

\begin{tabular}{|c|c|c|c|c|c|c|c|c|c|c|c|c|}
\hline & \multicolumn{4}{|c|}{$M_{1:}$ agency } & \multicolumn{4}{|c|}{$M_{2:}$ pathways } & \multicolumn{4}{|c|}{$Y$ : Subjective Well-being } \\
\hline & Coefficient & $S E$ & $\begin{array}{c}t \\
\text { Statistic }\end{array}$ & $\begin{array}{c}p \\
\text { Value }\end{array}$ & Coefficient & $S E$ & $\begin{array}{c}t \\
\text { Statistic }\end{array}$ & $\begin{array}{c}p \\
\text { Value }\end{array}$ & Coefficient & $S E$ & $\begin{array}{c}t \\
\text { Statistic }\end{array}$ & $\begin{array}{c}p \\
\text { Value }\end{array}$ \\
\hline Constant & $2.927 * *$ & .2031 & 14.412 & $<.001$ & $3.894 * *$ & .174 & 22.323 & $<.001$ & $3.814^{* *}$ & 1.051 & 3.629 & $<.001$ \\
\hline $\begin{array}{c}X: \\
\text { Self-efficacy }\end{array}$ & $.233 * *$ & .008 & 30.754 & $<.001$ & $.288 * *$ & .007 & 44.165 & $<.001$ & $.591 * *$ & .049 & 12.004 & $<.001$ \\
\hline$M_{1:}$ agency & & & & & & & & & $1.356^{*}$ & .094 & 14.397 & $<.001$ \\
\hline$M_{2: \text { pathways }}$ & & & & & & & & & $.999 *$ & .110 & 9.108 & $<.001$ \\
\hline$R^{2}$ & .268 & & & & .431 & & & & .369 & & & \\
\hline$F$ & $945.790^{* *}$ & & & & $1950.558 * *$ & & & & $502.018^{* *}$ & & & \\
\hline \multicolumn{7}{|c|}{ Bootstrap Analyses } & \multicolumn{2}{|c|}{ Effect } & \multicolumn{2}{|c|}{ Boot SE } & \multicolumn{2}{|c|}{$\begin{array}{c}95 \% \text { BCCI }[\mathrm{LL}, \\
\mathrm{UU}]\end{array}$} \\
\hline \multicolumn{7}{|c|}{ Indirect effect of Self-efficacy through agency on Subjective Well-being } & \multicolumn{2}{|c|}{.316} & \multicolumn{2}{|c|}{.026} & \multicolumn{2}{|c|}{$[.270, .370]$} \\
\hline \multicolumn{7}{|c|}{ Indirect effect of Self-efficacy through pathways on Subjective Well-being } & \multicolumn{2}{|c|}{.288} & \multicolumn{2}{|c|}{.033} & \multicolumn{2}{|c|}{$[.223, .353]$} \\
\hline \multicolumn{7}{|c|}{ Direct effect of Self-efficacy on Subjective Well-being } & \multicolumn{2}{|c|}{.591} & \multicolumn{2}{|c|}{.049} & \multicolumn{2}{|c|}{$[.495, .688]$} \\
\hline
\end{tabular}

Note. The coefficients are unstandardized. Bootstrap analyses based on 5,000 resamples; $\mathrm{LL}=$ lower limit; UL $=$ upper limit; $\mathrm{SE}=$ standard error; $\mathrm{BCCI}=$ bias corrected bootstrap confidence interval. ${ }^{* *} p<.001$ (two-sided)

\section{Discussion}

Results of this investigation generally support the mediation role of hope. We further examined the mediation effects of two component of hope. The positive relationship between hope, SWB and self-efficacy supports our assumption. We argue that self-efficacy predicts SWB in both ways, directly and indirectly through agency and pathways. The results confirm that two components of hope partially mediate the effect of self-efficacy on SWB. These results suggest that increased self-efficacy predicted greater agency and pathways thinking, which in turn predicted greater SWB. Moreover, two mediators explain more variance in SWB, compared with the situation that self-efficacy regress on SWB alone. For nurses, more hopeful thinking are employed in stress situations, a higher level of SWB is developed. It is confirmed that hope is an important protective factor for SWB.

Agency thinking helps nurses sustain their motivation to achieve goals, while pathways thinking helps nurses withdraw effort and find alternative routes to succeed. Moreover, pathways thinking frees nurses' resources to promote their life in other areas. It should be noted that goal alternation also would be associated with SWB. Both agency and pathways thinking may help a person avoid accumulated failure experiences, which may result in reduced SWB and enhanced psychological distress and depression. Hopeful nurses tend to have more positive emotion, which increases their motivation and SWB in turn. 
Self-efficacy contributes to one's hope. Self-efficacy is an optimistic construct. Nurses who are self-efficacious can deal with potential stressors effectively. On the contrary, nurses who suspect their own abilities to control stressful events suffer more distresses which may impair their level of functioning. In light of this, high self-efficacy nurses incline to perceive stressful events and obstacles with less apprehension and may regard this as a good chance for them to prove themselves. The results of this study demonstrated that high self-efficacy nurses incline to create more agency thinking to pursue goal, or more pathways thinking to generate alternative paths to succeed. This is consistent with previous finding that high self-efficacy nurses perceive that they are better capable of accomplishing tasks (Dunn et al., 2014). Prior research also supported that high self-efficacy affects how people cope with negative events (Asselmann, Wittchen, Lieb, Höfler, \& Beesdo-Baum, 2016). High self-efficacy nurses are able to generate more pathways and agency thinking than low self-efficacy nurses.

Hope is an important mediator in the association between self-efficacy and SWB. On one hand, improving self-efficacy enables nurses to employ high hope to combat with stressors, which in turn enhances SWB. On the other hand, nurses who lacked hopeful thinking often failed to work with high self-efficacy. Snyder's theory proposed that hopeful thoughts include goal-directed focus, finding available pathways, and being motivated to achieve goals (Snyder et al., 2002). In line with our findings, McGregor indicated that achievable goals is associated with well-being (McGregor \& Little, 1998). The findings indicate that we should pay high attention to those nurses with less self-efficacy, for the reason that they create low hope in dealing with stressors, which in turn decrease their SWB.

Limitations to this study were related to design. The study was a one-time measurement of the variables. The possibilities of generalizing to longitudinal cases need to be demonstrated. Future longitudinal studies would be helpful to further understand patterns of hope, self-efficacy, SWB. Also on the issue of generalization, this research study was conducted in China. It would be interesting to replicate the study in other countries. Moreover, cross-sectional data do not allow making causal conclusion.

Findings from the current study intend to provide implication for intervention strategies on how to improve nurses' SWB. Our study contributes to previous research (Magaletta \& Oliver, 1999; Salanova, Lorente, Chambel, \& Martínez, 2011) in the sense that hope is a powerful psychological mechanism that partially mediates the link between self-efficacy and SWB, at least among nurses.. This provides us information to design effective intervention to improve nurses' SWB. To improve SWB, it would be better to focus more on hope, which seems to have a remarkable influence on SWB. This study establishes an integrative model of self-efficacy, hope, and SWB that has a generative effect on each relevant literature. The current study not only enriches and extends our understanding of SWB, but also deepens our knowledge of hope.

\section{References}

Alarcon, G. M., Bowling, N. A., \& Khazon, S. (2013). Great expectations: A meta-analytic examination of optimism and hope. Personality \& Ind. Diff., 54(7), 821-827. https://doi.org/10.1016/j.paid.2012.12.004

Asselmann, E., Wittchen, H. U., Lieb, R., Höfler, M., \& Beesdo-Baum, K. (2016). Does low coping efficacy mediate the association between negative life events and incident psychopathology? A prospective-longitudinal community study among adolescents and young adults. Epidemiology \& Psychiatric Sciences, 25(2), 1-10. https://doi.org/10.1017/S204579601500013X

Bégat, I., Ellefsen, B., \& Severinsson, E. (2005). Nurses' satisfaction with their work environment and the outcomes of clinical nursing supervision on nurses' experiences of well-being -- a Norwegian study. Journal of nursing management, 13(3), 221-230. https://doi.org/10.1111/j.1365-2834.2004.00527.x

Bandura, A. (1997). Self-efficacy: The exercise of control: New York: Freeman.

Chan, M. H., Pittman, M. K., \& Munoz, R. T. (2013). The First Twenty Years of the Will and the Ways: An Examination of Score Reliability Distribution on Snyder's Dispositional Hope Scale. Journal of Happiness Studies, 14(3), 723-729. https://doi.org/10.1007/s10902-012-9351-5

Diener, E., \& Ryan, K. (2009). Subjective well-being: A general overview. South African Journal of Psychology, 39(4), 391-406. https://doi.org/10.1177/008124630903900402

Duggleby, W., Cooper, D., \& Penz, K. (2009). Hope, Self-Efficacy, Spiritual Well-Being, and Job Satisfaction. Journal of Advanced Nursing, 65(11), 2376-2385. https://doi.org/10.1111/j.1365-2648.2009.05094.x

Dunn, K. E., Osborne, C., \& Link, H. J. (2014). High-Fidelity Simulation and Nursing Student Self-Efficacy: Does Training Help the Little Engines Know They Can? Nursing Education Perspectives, 35(6), 403-404. https://doi.org/10.5480/12-1041.1 
Geraghty, A. W. A., Wood, A. M., \& Hyland, M. E. (2010). Dissociating the facets of hope: Agency and pathways predict dropout from unguided self-help therapy in opposite directions. Journal of Research in Personality, 44(1), 155-158. https://doi.org/10.1016/j.jrp.2009.12.003

Hayes, A. F. (2013). Introduction to Mediation, Moderation, and Conditional Process Analysis: A Regression-Based Approach.

Herth, K. (1990). Relationship of hope, coping styles, concurrent losses, and setting to grief resolution in the Elderly Widow(er). Research in Nursing \& Health, 13(2), 109-117. https://doi.org/10.1002/nur.4770130207

Löve, J., Moore, C. D., \& Hensing, G. (2012). Validation of the Swedish translation of the General Self-Efficacy scale. Quality of Life Research, 21(7), 1249-1253. https://doi.org/10.1007/s11136-011-0030-5

Magaletta, P. R., \& Oliver, J. M. (1999). The hope construct, will, and ways: their relations with self-efficacy, optimism, and general well-being. Journal of Clinical Psychology, 55(5), 539-551. https://doi.org/10.1002/(SICI)1097-4679(199905)5553.0.CO;2-G

McGregor, I., \& Little, B. R. (1998). Personal projects, happiness, and meaning: on doing well and being yourself. J. of Personality \& Social Psy., 74(2), 494-512. https://doi.org/10.1037//0022-3514.74.2.494

Rigtering, J., \& Weitzel, U. (2013). Work context and employee behaviour as antecedents for intrapreneurship. International Entrepreneurship and Management Journal, 9(3), 337-360.

Salanova, M., Lorente, L., Chambel, M. J., \& Martínez, I. M. (2011). Linking transformational leadership to nurses\&rsquo; extra - role performance: the mediating role of self - efficacy and work engagement. Journal of Advanced Nursing, 67(10), 2256-2266. https://doi.org/10.1111/j.1365-2648.2011.05652.x

Shea, F., \& Hurley, E. (1964). Hopelessness and Helplessness. Perspectives in Psychiatric Care, 2(1), 32-38. https://doi.org/10.1111/j.1744-6163.1964.tb01391.x

Snyder, C. R., Shorey, H. S., Cheavens, J., Pulvers, K. M., Adams, V. H., III, \& Wiklund, C. (2002). Hope and Academic Success in College. J. of Edu. Psy., 94(4), 820-826. https://doi.org/10.1037/0022-0663.94.4.820

Steca, P., Abela, J. R. Z., Monzani, D., Greco, A., Hazel, N. A., \& Hankin, B. L. (2014). Cognitive Vulnerability to Depressive Symptoms in Children: The Protective Role of Self-efficacy Beliefs in a Multi-Wave Longitudinal Study. J. of Abnormal Child Psy., 42(1), 137-148. https://doi.org/10.1007/s10802-013-9765-5

Stump, G. S., Husman, J., \& Brem, S. K. (2012). The Nursing Student Self-Efficacy Scale: Development Using Item Response Theory. Nursing Research, 61(3), 149-158. https://doi.org/10.1097/NNR.0b013e318253a750

Taylor, J., Poston II, W. C., Haddock, C. K., Blackburn, G., Heber, D., Heymsfield, S., \& Foreyt, J. (2003). Psychometric characteristics of the General Well-Being Schedule (GWB) with African-American women. Quality of Life Research, 12(1), 31-39. https://doi.org/10.1023/A:1022052804109

Waddell, J., Spalding, K., Canizares, G., Navarro, J., Connell, M., Jancar, S., . . Victor, C. (2015). Integrating a Career Planning and Development Program into the Baccalaureate Nursing Curriculum: Part I. Impact on Students' Career Resilience. International Journal of Nursing Education Scholarship, 12, 163.

Weiss, D., Freund, A. M., \& Wiese, B. S. (2012). Mastering developmental transitions in young and middle adulthood: The interplay of openness to experience and traditional gender ideology on women's self-efficacy and subjective well-being. Developmental Psy., 48(6), 1774. https://doi.org/10.1037/a0028893

Yavas, U., Babakus, E., \& Karatepe, O. M. (2013). Does hope moderate the impact of job burnout on frontline bank employees' in-role and extra-role performances? International Journal of Bank Marketing, 31(1), 56-70(15). https://doi.org/10.1108/02652321311292056

Zhang, J. X., \& Schwarzer, R. (1995). Measuring optimistic self-beliefs: A Chinese adaptation of the General Self-Efficacy Scale. Psychologia An International Journal of Psychology in the Orient, 38(3), 174-181.

Zhao, X., Lynch, J. G., \& Chen, Q. (2010). Reconsidering Baron and Kenny: Myths and Truths about Mediation Analysis. Journal of Consumer Research, 37(2), 197-206. https://doi.org/10.1086/651257

\section{Copyrights}

Copyright for this article is retained by the author(s), with first publication rights granted to the journal.

This is an open-access article distributed under the terms and conditions of the Creative Commons Attribution license (http://creativecommons.org/licenses/by/4.0/). 